\title{
A STUDY ON THE STATUS OF FURNITURE MANUFACTURING INDUSTRIES IN MORATUWA AREA
}

\author{
T A D S Jayapala' and H S Amarasekera² \\ i Forest Department \\ 2Department of Forestry and Environment Science, \\ University of Sri Jayewardenepura
}

\begin{abstract}
Moratuwa area has a long history of furniture industry in Sri Lanka. In the present study, furniture manufacturing industry (FMI) in Moratuwa was studied using two questionnaire surveys. The main raw materials, manufacturing process, technological level, furniture designing methods, seasoning methods, waste disposal methods, educational and sociological aspects of workers of the FMI were studied. In addition, data were collected on furniture marketing from the Ratmalana furniture permit-issuing center of the Forest Department. Raw material supplies (timber logs) into the Moratuwa area were also studied at five different locations including timber-checking stations.
\end{abstract}

The study revealed that the Moratuwa area consists of considerable amount of mechanized carpentry sheds and some associate with furniture shops or saw mills. 83\% of furniture is manufactured using heavy wood species and 17\% using light wood species. Teak is the most popular timber species followed by Satin and Nadun. Most of the timbers used in the industry are air dried, while others are kiln-dried. Three common methods are observed for designing of furniture: based on consumer preference, traditional designs by carpenters and use of designs from foreign catalogues. Furniture can be categorized into six broad categories, based on their quality and finishing level. Semi- finished Furniture are mostly sold in bulk to furniture dealers in out side areas, and after transportation, they are finished and sold based on regional requirements.

The total number of furniture production per month is estimated as 63,612 units, when 41 furniture items are considered. Teak Cabinets, Teak Elmira, and Teak Chairs are the main manufacturcd items. The overall monthly income from all the FMI of Moratuwa area is estimated to be Rs. $\mathbf{5 4 . 0 5}$ million.

Wooden wastes mainly consist of sawdust/ slabs (2854 cum) and fuel wood ( $1850 \mathrm{cu} . \mathrm{m})$, which arc estimated to value approximately Rs. $569,270.00 .15 \%$ of this wooden waste is used for cooking purposes in the FMI of Moratuwa area. 34\% is used for other purposes such as agricultural and poultry industries and as fuel for kilns of the brick industry. However $44 \%$ of wooden wastes is not utilized and is disposed by burning.

The total number of workers is estimated as 3515 workers which comprises, skilled carpenters $(68 \%)$, semi skilled carpenters $(11 \%)$, laborers $(7 \%)$, other category workers (5\%), managers (4\%) and supervisors (4\%). The dominant age class in the FMI is 41 55 years, which represents 44 percent of the total workers. 192 children (out of 378) of the workers are employed in FMI; which accounts 51 percent children of the workers join the

FMI. The educational levels of the workers are low and they have gained their skills from their fathers and forefathers.

Proceedings of the Ninth Annual Forestry and Environment Symposium 2003 of the Department of Forestry and Environmental Science, University of Sri Jayewardenepura. Sri Lanka 